\title{
In Vivo Therapeutic Silencing of Hypoxia-Inducible Factor 1 Alpha (HIF-1 $\alpha$ ) Using Single-Walled Carbon Nanotubes Noncovalently Coated with siRNA
}

\author{
Geoffrey Bartholomeusz ${ }^{1, \dagger}(\varangle)$, Paul Cherukuri ${ }^{1,2, \dagger}$, John Kingston ${ }^{1}$, Laurent Cognet ${ }^{2,3}$, Robert Lemos Jr. ${ }^{1}$, \\ Tonya K. Leeuw ${ }^{2}$, Laura Gumbiner-Russo ${ }^{1}$, R. Bruce Weisman ${ }^{2}$, and Garth Powis ${ }^{1}$ \\ ${ }^{1}$ Department of Experimental Therapeutics, University of Texas M. D. Anderson Cancer Center, 1515 Holcombe Blvd., Houston, TX \\ 77030, USA \\ ${ }^{2}$ Department of Chemistry, Center for Biological and Environmental Nanotechnology, and Institute of Biosciences and Bioengineering, \\ Rice University, 6100 Main Street, Houston, TX 77005, USA \\ ${ }^{3}$ Centre de Physique Moléculaire Optique et Hertzienne, Université Bordeaux 1 and CNRS, 351 cours de la Libération, 33405 Talence \\ Cedex, France
}

Received: 11 December 2008/Revised: 20 January 2009/Accepted: 28 January 2009

(C) Tsinghua University Press and Springer-Verlag 2009. This article is published with open access at Springerlink.com

\begin{abstract}
A new approach is described for delivering small interfering RNA (siRNA) into cancer cells by noncovalently complexing unmodified siRNA with pristine single-walled carbon nanotubes (SWCNTs). The complexes were prepared by simple sonication of pristine SWCNTs in a solution of siRNA, which then served both as the cargo and as the suspending agent for the SWCNTs. When complexes containing siRNA targeted to hypoxiainducible factor 1 alpha (HIF-1 $\alpha$ ) were added to cells growing in serum containing culture media, there was strong specific inhibition of cellular HIF- $1 \alpha$ activity. The ability to obtain a biological response to SWCNT/ siRNA complexes was seen in a wide variety of cancer cell types. Moreover, intratumoral administration of SWCNT- HIF- $1 \alpha$ siRNA complexes in mice bearing MiaPaCa-2/HRE tumors significantly inhibited the activity of tumor HIF-1 $\alpha$. As elevated levels of HIF- $1 \alpha$ are found in many human cancers and are associated with resistance to therapy and decreased patient survival, these results imply that SWCNT/siRNA complexes may have value as therapeutic agents.
\end{abstract}

\section{KEYWORDS}

siRNA, single-walled carbon nanotubes, anti-cancer therapy, in vivo delivery agent

\section{Introduction}

The hypoxic microenvironment present in rapidly proliferating solid tumors makes them among the most aggressive and difficult tumors to treat [1,2].
Unlike the balance achieved in normal tissues, the consumption of oxygen in these tumors exceeds oxygen delivery from tumor blood vessels [3]. Clinically, treatment failure results from the resistance of hypoxic cancer cells to both chemotherapy [4] and

Address correspondence to gbarthol@mdanderson.org

${ }^{\dagger}$ These two authors contributed equally to the design and implementation of this study. 
radiotherapy $[5,6]$.

Hypoxia-inducible factor 1 alpha (HIF-1 $\alpha$ ) is a transcription factor whose activity is increased in human cancers in response to intratumoral hypoxia $[7,8]$. HIF-1 $\alpha$ plays important roles in many aspects of cancer biology, including cell proliferation, angiogenesis, invasion, and glycolysis, through the transcriptional regulation of a large number of genes [9]. The significance of the contribution of HIF-1 $\alpha$ to tumor growth is well documented [10-13], and mouse xenograft studies have clearly demonstrated that the inhibition of HIF- $1 \alpha$ activity suppresses tumor growth $[6,11,14]$. HIF- $1 \alpha$ is thus an attractive target for the development of anti-cancer agents. Several small-molecule inhibitors of HIF- $1 \alpha$ have been identified, but their selectivity remains undefined. Selective inhibition of HIF-1 $\alpha$ activity is an attractive approach to suppress tumor growth that may be achievable using siRNA as the therapeutic agent.

Exogenously synthesized, 19 to 22 base pair (bp) double-stranded small interfering RNA (siRNA) can activate the endogenous RNA interference (RNAi) pathway within mammalian cells and serve as a powerful tool for selective gene silencing. While RNAi holds great promise for targeted cancer therapy [15], one of the key challenges is its delivery into tumor cells.

Single-walled carbon nanotubes (SWCNTs) are a new class of nanomaterials with significant biological potential. They are possible vehicles for delivering siRNA into mammalian cells, as they are capable of transporting various biological molecules into cancer cells through endocytosis, with negligible toxicity to the cells [16-20]. However, before they can be used in biomedical applications, the hydrophobic pristine SWCNTs must be converted into a stable suspension in aqueous solution [21]. This can be accomplished by noncovalently coating SWCNTs with surfactants or polymers, or by covalently functionalizing their side walls with suitable water-soluble groups [2226]. SWCNTs functionalized with covalently bound siRNA have been used to deliver siRNA into cancer cells in both in vitro tissue culture and in tumorbearing mice $[17,27,19]$. In addition, SWCNTs have been noncovalently coated with phospholipids that were covalently linked to siRNA [27]. These complexes were then delivered into cancer cells, T-cells, and human primary cells to knock down targeted genes. In both of these approaches, an intracellular chemical reaction is subsequently needed to break the covalent link and release the siRNA cargo [28].

In the present study we have adopted an alternative approach in which unmodified siRNA serves both to noncovalently solubilize SWCNTS and also acts as the cargo. This method was suggested by the reported ability of single-stranded DNA (ssDNA) to coat pristine SWCNTs and give stable aqueous suspensions [29-31]. The DNA in such complexes apparently forms a helical wrapping around the SWCNTs in which the bases interact closely with the hydrophobic surface of the nanotubes while the sugar-phosphate groups are exposed to water [29]. Optimum binding was observed to be dependent on base composition [32], with the best SWCNT solubilization obtained with a sequence containing alternating $\mathrm{G}$ and $\mathrm{T}$ and total lengths from 20 to 90 bp. Although the nanotube-coating interactions in such complexes must differ from those containing a double-stranded oligonucleotide such as siRNA, formation of our SWCNT/siRNA noncovalent complexes also required only simple ultrasonic agitation rather than chemical reactions. We found that the siRNA in these complexes retained its biological activity and readily entered cells-even in the presence of serum-as demonstrated by observation of the RNAi response in exposed cell culture. In addition, intratumoral administration of SWCNT/siRNA complexes targeting HIF-1 $\alpha$ was found to significantly reduce HIF- $1 \alpha$ activity in tumor-bearing mice. Our study demonstrates the potential for using pristine SWCNTs solubilized by siRNA as a therapeutic agent for cancer treatment.

\section{Experimental}

\subsection{Preparation of noncovalent complexes of SWCNTs with siRNA}

SWCNTs were produced through the high-pressure carbon monoxide (HiPco) process [33]. Raw 
HiPco SWCNT product was added to an aqueous buffer solution (100 mM KCL, 30 mM HEPES$\mathrm{KOH}$ [pH 7.5], $1 \mathrm{mM} \mathrm{MgCL}_{2}$ ) containing $20 \mathrm{~mol} /$ L solubilized pooled siRNA [ (siRNA targeting HIF- $1 \alpha($ HIF- $1 \alpha)$ 5'-CCUGUGUCUAAAUCUG AAC-3', 5'CUACCUUCGUGAUUCUGUUU-3', G C A C A A U A G A C A G C G A A A C - $3^{\prime}$, 5'-CUACUUUCUUAAUGGCUUA), polo-like kinase 1 (PLK1), 5'-CAACCAAAGUCGAAUAU UGAUU-3, 5' -CAAGAAGAAUGAAUACAGUU U-3', 5'-GAAGAUGUCCAUGGAAAUAUU-3', 5'-CAACACGCCUCAUCCUCUAUU-3', Kinesin superfamily protein (Kif11), 5'-CGUCUUUAGAU UCCUAUAU-3', 5' -GUUGUUCCUACUUCAGAUA -3', 5'-GUCGUCUUUAGAUUCCU AU-3', 5'-GAUC UACCGAAAGAGUCAU-3'], non-targeting siRNA 5'-UAGCGACAUU UGUGUAGUU-3' or siTox, which were all purchased from Dharmacon Inc, IL. When siTox is introduced into the cell it does not activate the RNAi response but instead induces the interferon response resulting in the non-specific killing of the cell; it therefore serves as a good positive control in the determination of transfection efficiency. This mixture was sonicated (Sonics, Vibracell) at $25^{\circ} \mathrm{C}$ using two $15 \mathrm{~s}$ pulses at settings of $130 \mathrm{~W}$, $20 \mathrm{kHz}$, and $40 \%$ amplitude. The sonicated samples were then centrifuged at $15,000 \mathrm{~g}$ for $5 \mathrm{~min}$. The resulting pellet comprised of bundled SWCNTs was discarded and the supernatant was transferred into a clean tube and centrifuged for an additional $1 \mathrm{~min}$ with the same settings. The resulting supernatant contained SWCNTs noncovalently suspended by coatings of adsorbed siRNA. Near-infrared (NIR) fluorescence spectroscopy indicated that these samples contained predominantly individually suspended SWCNTs rather than nanotube aggregates. These SWCNT/siRNA complexes were stable and retained their biological activity following storage for 30 days at $4{ }^{\circ} \mathrm{C}$. Longer periods of time have not been tested but we predict that our SWCNT/siRNA complexes will retain biological activity for longer periods of storage at $4{ }^{\circ} \mathrm{C}$.

\subsection{Cell culture and cellular incubation with SWCNT/siRNA complexes}

MiaPaCa2-HRE (a pancreatic cell line with an HIF-1 $\alpha /$ luciferase reporter) cells were incubated in growth media consisting of high-glucose DMEM supplemented with $10 \%$ fetal calf serum (all reagents from HyClone). To determine the internalization rate of non-targeting siRNAsolubilized SWCNTs, $50 \mu \mathrm{L}$ of the complex (final SWCNT concentration $\sim 1.25 \mathrm{mg} / \mathrm{L}$ ) was added to cells $\left(\sim 2 \times 10^{5}\right.$ cells / well $)$ that had been incubated for $18 \mathrm{~h}$ in $1 \mathrm{~mL}$ of media in a 6 -well plate. Incubation with the SWCNT/siRNA complex was continued for 1,3 , and $6 \mathrm{~h}$. After incubation, media was removed from the wells, the cells were washed once in phosphate buffered saline (PBS) and were then detached from the surface by adding $0.25 \%$ trypsin (Invitrogen). The detached cells were washed with growth media to inactivate the trypsin and then washed again with PBS. These cells were resuspended in $1 \mathrm{~mL}$ of growth media, transferred onto a circular glass cover slip in a well of a new 6-well plate, and incubated at $37{ }^{\circ} \mathrm{C}$ in a humid environment for $\sim 20 \mathrm{~h}$. NIR fluorescence microscopy was then used to identify internalized SWCNTs.

To investigate the biological activities of SWCNT/ siRNA complexes, $20 \mu \mathrm{L}$ of each sample was added to cells $\left(\sim 2 \times 10^{5}\right.$ cells/well $)$ in $100 \mu \mathrm{L}$ of media containing $10 \%$ FCS in 96 -well plates. The plates were incubated at $37^{\circ} \mathrm{C}$ in a humidified chamber for $\sim 18 \mathrm{~h}$ prior to, and for $72 \mathrm{~h}$ following, addition of the complexes. To determine the ability of the complexes to suppress HIF- $1 \alpha$ activity or silence the HIF- $1 \alpha$ protein, treated cells incubated under normoxia for $72 \mathrm{~h}$ were incubated for a further $18 \mathrm{~h}$ under hypoxic conditions ( $1 \%$ oxygen).

\subsection{Cell viability}

Cell proliferation reagent (WST-1, Roche, Mannheim, Germany) was added to cells in media to a final concentration of $10 \%$, and the cells were incubated for $30 \mathrm{~min}$ at $37{ }^{\circ} \mathrm{C}$ in a humidified incubator. The absorbance of the sample was then measured relative to a background control using a microplate reader (POLARstar OPTIMA, BMG Labtech) at $420-480 \mathrm{~nm}$.

\subsection{Reporter assay}

The MiaPaCa2-HRE cell line used in this study was 
generated in order to stably express the promoter sequence of a target gene of HIF- $1 \alpha$ comprising the HIF- $1 \alpha$ binding hypoxia response element (HRE) fused to the luciferase gene. At the end of the experiment, $100 \mu \mathrm{L}$ of media was removed from each well of the 96-well plate and replaced with 50 $\mu \mathrm{L}$ of the luciferase reagent $(25 \mathrm{mM}$ tricine, $0.5 \mathrm{mM}$ EDTA-NA $2,0.54 \mathrm{mM}$ sodium triphosphate, 16.3 $\mathrm{mM} \mathrm{MgSO}_{4} \cdot 7 \mathrm{H}_{2} \mathrm{O}, 0.3 \%$ Triton X-100, $0.1 \% \mathrm{w} / \mathrm{v}$ dithiothreitol, $1.2 \mathrm{mM}$ ATP, $50 \mathrm{mM}$ luciferin and $270 \mathrm{mM}$ coenzyme A). The plates were incubated at room temperature for $5 \mathrm{~min}$. Sample luminescence was measured relative to a background control using a microplate reader (POLARstar OPTIMA, BMG Labtech).

\subsection{Spectroscopy and microscopy of SWCNTs}

The NIR emission spectrum of the siRNA-suspended SWCNTs was measured using $658 \mathrm{~nm}$ excitation in a model NS1 NanoSpectralyzer (Applied NanoFluorescence, Houston, TX). NIR fluorescence microscopy was performed using a custom-built apparatus containing diode laser excitation sources emitting at 658 and $785 \mathrm{~nm}$ [34]. Individual SWCNTs internalized into cells were imaged with a custombuilt NIR fluorescence microscope using $785 \mathrm{~nm}$ excitation, a $60 \times$ oil-immersion objective, and a 946 $\mathrm{nm}$ long-pass filter in the collection path. Bright field images were taken using the $60 \times$ objective.

\subsection{Statistical analysis}

Statistical analyses were performed with commercially available software. We used single regression analysis to assess the ratio of HIF- $1 \alpha$ activity after treatment with $100 \mu \mathrm{L}$ sample volume; SWCNT concentration $\sim 4 \mathrm{mg} / \mathrm{L}$; siRNA concentration $\sim 2 \mu \mathrm{M}$, with the percentage luciferase expression after SWCNT/siRNA treatment as the dependent variable. Student's $t$-tests were used to compare the ratio of luciferase intensity within the tumor between mice treated with SWCNT/siRNA. Comparisons of mice treated with siRNA targeting HIF-1 $\alpha$ (siHIF), SWCNT/non-targeting siRNA (SWCNT/SC), or siRNA targeting HIF-1 $\alpha$ (siHIF) were computed by two-way ANOVA. Statistical significance was defined as a $P$ value of $<0.05$.

\subsection{Animal studies}

1.7.1 Testing of the biological activity of the SWCNT/ siRNA complexes in $0.9 \%$ saline solution

SWCNTs were complexed with $20 \mu \mathrm{M}$ of siRNA targeting polo-like kinase1 (PLK1) in a $0.9 \% \mathrm{NaCl}$ solution using the procedure described above. A 20 $\mu \mathrm{L}$ portion of each sample was added to cells $(\sim 2 \times$ $10^{5}$ cells/well) in $100 \mu \mathrm{L}$ of media containing $10 \%$ FCS in 96-well plates. The treated cells were incubated at $37^{\circ} \mathrm{C}$ in a humid chamber for $72 \mathrm{~h}$ and their viability was determined by the WST-1 assay.

\subsubsection{Injection of mice with MiaPaCa-2/ HRE pancreatic cancer cells}

The cells were grown in humidified 95\% air, 5\% $\mathrm{CO}_{2}$ at $37{ }^{\circ} \mathrm{C}$ in DMEM supplemented with $10 \%$ FCS. Cells $\left(10^{7}\right)$ in log cell growth were suspended in 0.1 mL Matrigel (Becton Dickinson Biosciences, Palo Alto, CA) and injected subcutaneously (s.c.) into the flanks of female Swiss athymic nude nu/nu mice (Department of Experimental Radiation Oncology, University of Texas M. D. Anderson Cancer Center, Houston, TX). Tumor diameters at right angles $\left(d_{\text {short }}\right.$ and $d_{\text {long }}$ ) were measured twice weekly with electronic calipers and converted to volume by the formula [35]: volume $=d^{2}{ }_{\text {short }} \times d_{\text {long }} / 2$. When the tumors reached $150 \mathrm{~mm}^{3}$, the mice were stratified into groups of eight animals having approximately equal mean tumor volumes. Intratumoral administration of the SWCNT/siRNA complexes was then performed twice per week for three weeks $(100 \mu \mathrm{L}$ sample volume; SWCNT concentration $\sim 4 \mu \mathrm{M}$; siRNA concentration $\sim 2 \mu \mathrm{M})$. The intratumoral injections were administered with the mice positioned dorsally and their tumors divided into four quadrants; each injection was administered in a new quadrant using a clockwise rotation. Tumor volume was measured twice weekly until the tumor reached $1500 \mathrm{~mm}^{3}$ or more or became necrotic, at which time the animals were euthanized.

\subsection{Detecting luciferase expression in vivo: Bioluminescence imaging}

After 20 days of tumor development, mice were imaged twice weekly using the IVIS Lumina 
(Caliper Life Sciences). Mice were pair-matched into groups according to their tumor volumes. Before imaging, D-luciferin (Caliper Life Sciences) was given to each mouse via intraperitoneal (i.p.) injection at a dose of $150 \mathrm{mg} / \mathrm{kg}$ and allowed to distribute for $5 \mathrm{~min}$. After they were anesthetized in the chamber with $3 \%$ isoflurane, mice were imaged using a $12.5 \mathrm{~cm}$ field of view and a $15 \mathrm{~s}$ exposure time. Their respective bioluminescence intensities were determined by calculating the photon flux using Living Image software (version 3.0). Photon flux was represented as photons / $\left(\mathrm{s} \cdot \mathrm{cm}^{2} \cdot \mathrm{sr}\right)$ in the region of interest (ROI) and surrounding bioluminescence signal provided by the tumor. The ROIs were then used to determine the photon flux, expressed as percent photon flux of vehicle control values [36].

\subsection{Western blotting}

Cell pellets were resuspended in modified RIPA lysis buffer (10 mM NaCL, 1\% NP-40, 0.5\% sodium deoxycholate, $0.1 \% \mathrm{SDS}, 50 \mathrm{mM}$ trishydrochloric acid [pH 7.5] with inhibitors $(20 \mathrm{mg} / \mathrm{mL}$ aprotinin, $1 \mathrm{mM}$ sodium fluoride, $2 \mathrm{mM}$ sodium orthovanadate, $0.5 \mathrm{mM}$ phemylmethanesulfonyl fluoride and $250 \mathrm{mg} / \mathrm{mL}$ benzamidine) in ice for $30 \mathrm{~min}$ and centrifuged at $15,000 \mathrm{~g}$ for 30 min to collect whole cell lysates. The lysates (50 $-60 \mu \mathrm{g}$ ) were run on $10 \%$ SDS-polyacrylamide electrophoresis (PAGE) gels and transferred to a polyvinylidene difluoride membrane. Western blotting was performed with specific primary antibodies and peroxidase-conjugated AffiniPure anti-mouse and anti-rabbit secondary antibodies (Jackson ImmunoResearch Laboratories). Proteins were visualized with ECL Plus enhanced chemiluminescence reagents (Amersham Biosciences, Piscataway, NJ).

\section{Results and discussion}

\subsection{Suspension of pristine SWCNTs in siRNA}

Nucleic acids, including single-stranded DNA and RNA, have previously been shown to be capable of suspending and dispersing SWCNTs in water through noncovalent association [29]. We found that sonication of pristine SWCNTs in aqueous buffer in the absence of siRNA failed to produce a stable suspension (Fig. 1 (a)). However, equivalent processing in the presence of siRNA gave stable, homogeneous suspensions (Fig. 1 (b)). As shown in Fig. 1 (c), these suspensions displayed strong nearinfrared (NIR) fluorescence between 900 and 1600 $\mathrm{nm}$, which is characteristic of individual but not aggregated SWCNTs [37]. We conclude that pristine, individualized SWCNTs are made water-compatible by coating with siRNA.

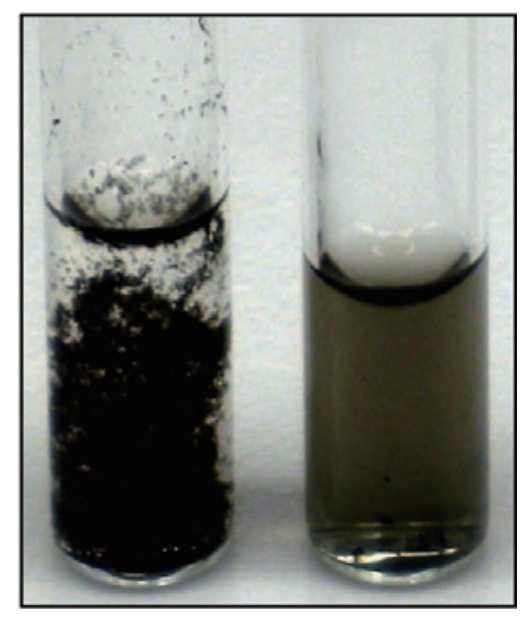

(a)

(b)

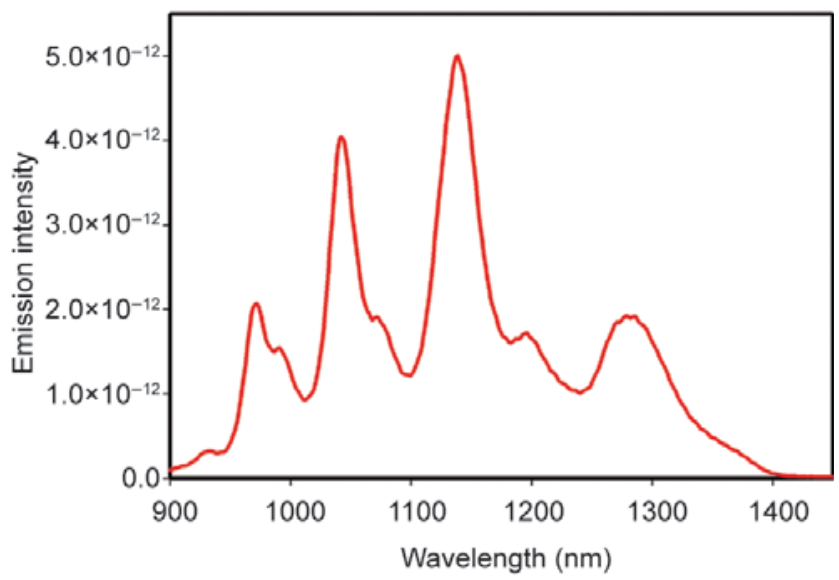

(c)

Figure 1 Photographs of pristine single-walled carbon nanotubes (SWCNTs) dispersed in 5x siRNA buffer: (a) SWCNTs alone; (b) siRNA-solubilized SWCNT solution; (c) normalized emission spectra (using $658 \mathrm{~nm}$ excitation) of pristine SWCNTs solubilized with SiRNA 


\subsection{Rapid internalization of siRNA-solubilized pristine SWCNTs into pancreatic cancer cells}

We next investigated whether siRNA-coated SWCNTs could be internalized into cells in tissue culture. Previous studies indicate that covalently modified SWCNTs can enter cells rather quickly. We exposed MiaPaCa2-HRE cultures to SWCNT/ siRNA complexes for 1,3 , and $6 \mathrm{~h}$ in order to monitor internalization. NIR fluorescence microscopy of the treated cells clearly revealed internalized SWCNTs (Fig. 2). These were identified by their characteristic emission wavelengths and their strong dependence of emission intensity on excitation beam polarization. In addition, NIR fluorescent particles were found only in cells incubated with suspended SWCNTs and not in SWCNT-free control samples. As the sample area irradiated by the laser beam was smaller than the image field, some cells in each image do not show NIR emission even though they contain internalized SWCNTs. We observed that incubation for $1 \mathrm{~h}$ with the SWCNT/siRNA complexes resulted in SWCNT uptake by approximately $40 \%$ of cells. Incubation for $3 \mathrm{~h}$ or $6 \mathrm{~h}$ resulted in nanotube uptake by larger fractions of cells, and the average SWCNT content per cell also increased with incubation time. Although the concentration of internalized nanotubes varied substantially from cell to cell, after incubation for $6 \mathrm{~h}$ more than $90 \%$ of the cells showed detectable SWCNTs.

\subsection{Delivery of siRNA capable of inducing a biological response by internalized SWCNTs}

Having found that brief sonication successfully produced SWCNT/siRNAi complexes capable of cellular internalization, we performed experiments to see whether the internalized siRNA was biologically active. We sonicated a mixture of pristine SWCNTs and siTox (known to induce interferon-dependent killing) and added $20 \mu \mathrm{L}$ of the complex (containing $5 \mathrm{mg} / \mathrm{L}$ SWCNTs and $5 \mu \mathrm{M}$ siTox) to MiaPaCa-HRE (human pancreatic cancer) cells growing in a 96-well

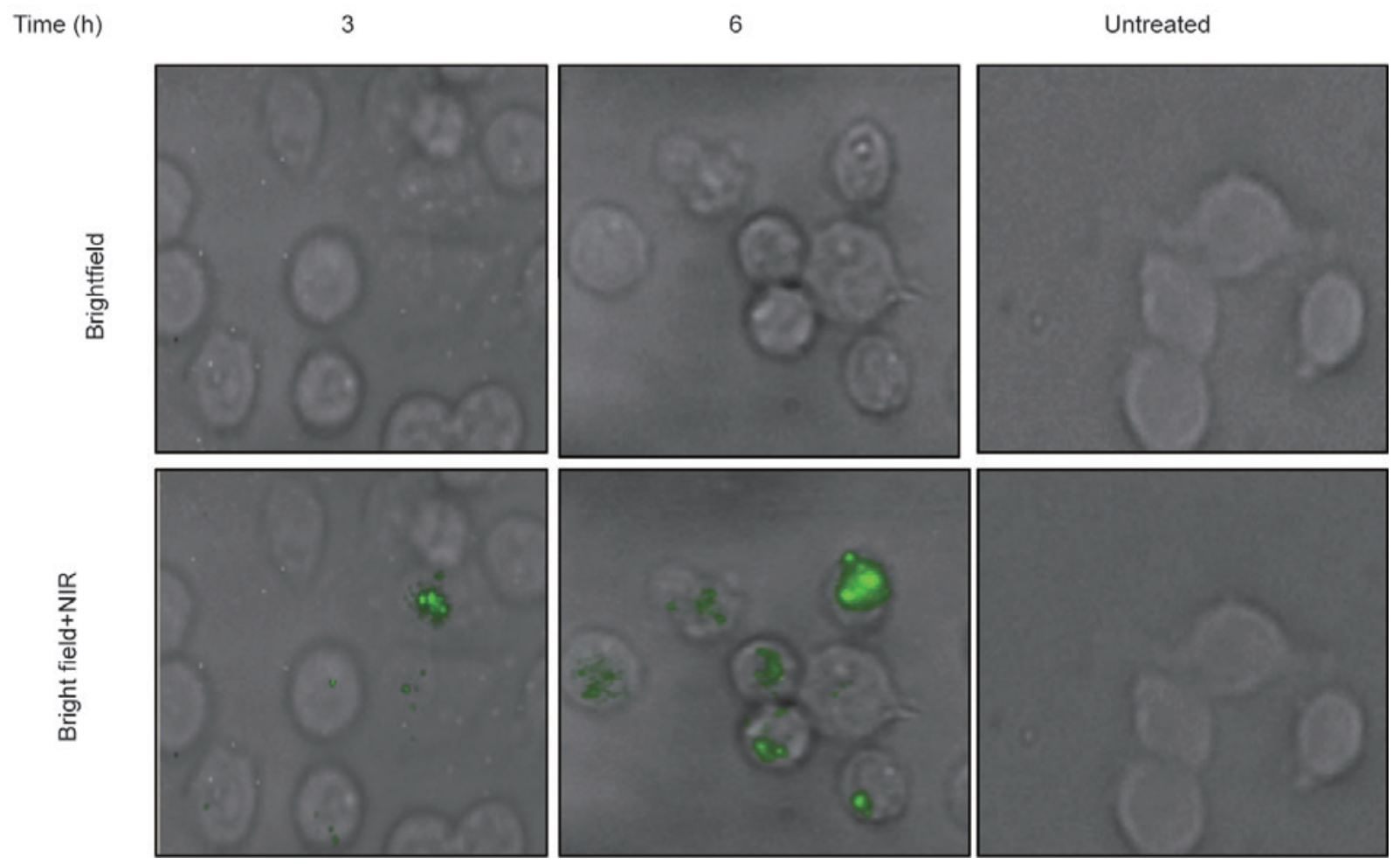

Figure 2 Bright field and NIR images of incubated cells showing internalized SWCNTs. MiaPaCa2-HRE pancreatic cells were incubated with SWCNT/siRNA complexes for the times indicated, harvested by trypsinization, washed and re-seeded on circular glass cover slips placed in a well of a 6 -well plate. After $20 \mathrm{~h}$ of incubation at $37^{\circ} \mathrm{C}$, cells growing on the cover slips were imaged in bright field and by NIR fluorescence microscopy. In the overlaid images, NIR emission from internalized SWCNTs is displayed in green. No SWCNTS were detected in untreated cells 
plate. Each well contained $100 \mu \mathrm{L}$ of medium with $10 \%$ FCS. Controls included untreated cells, and cells treated with $20 \mu \mathrm{L}$ of a complex of SWCNT and non-targeting siRNA (SWCNT/SC) (containing $5 \mathrm{mg} / \mathrm{L}$ SWCNTs and $5 \mu \mathrm{M}$ siSC), $20 \mu \mathrm{L}$ of SWCNTs solubilized by $10 \%$ FCS, buffer alone, and free uncomplexed siTox (final concentration $5 \mu \mathrm{M}$ ). At $72 \mathrm{~h}$ after treatment, we observed a $\sim 90 \%$ decrease in viability of cells treated with the SWCNT/siTox complex (Fig. 3). This effect was specific to the SWCNT/siTox complex, as none of the controls showed decreased cell viability. We conclude that the preparative sonication does not damage the siRNA and that siRNA is delivered into cells by pristine SWCNTs in a biologically active form. It is notable that serum did not inhibit the transfection process.

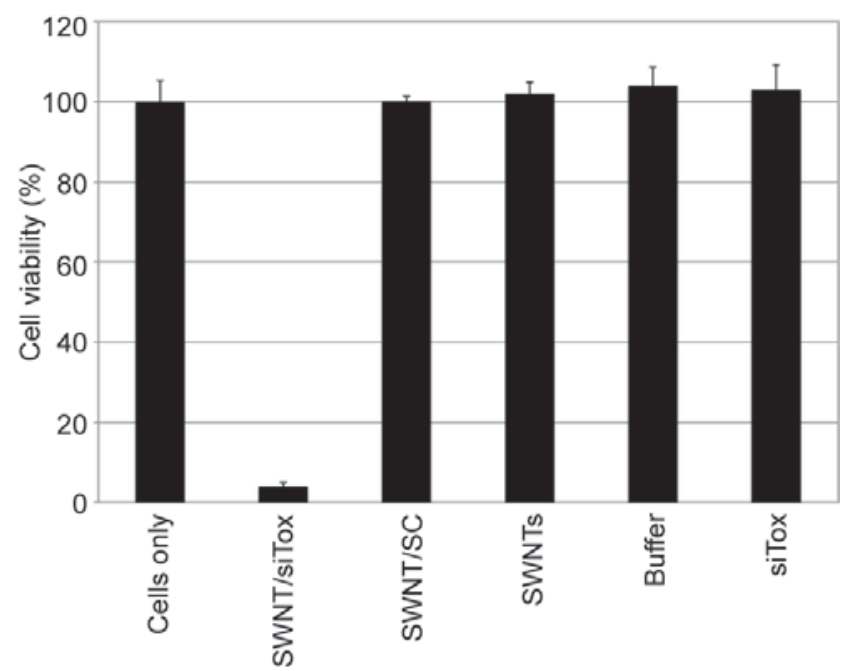

Figure 3 Pristine SWCNTS deliver biologically active siRNA into MiaPaCa-HRE pancreatic cancer cells. SWCNTS solubilized with either Tox siRNA (SWCNT/siTox), non-targeting siRNA(SWCNT/SC) or $10 \%$ FCS (SWCNTS), buffer alone or free Tox siRNA (siTox), were added to cells in growth media containing $10 \%$ FCS and incubated at $37{ }^{\circ} \mathrm{C}$ for $72 \mathrm{~h}$ prior to determination of cell viability

\subsection{RNAi response induced by siRNA delivery into cells by pristine SWCNTs}

We next investigated whether SWCNT/siRNA complexes could activate a specific RNAi response. For this our model was the MiaPaCa-HRE pancreatic cancer cell line (see Experimental section). Changes in HIF- $1 \alpha$ activity can be accurately monitored in these cells by measuring the levels of luciferase expression.
MiaPaCa-HRE cells were treated with SWCNTs complexed with either an siRNA specifically targeting HIF-1 $\alpha$ (siHIF), or a non-targeting siRNA (siSC), at final concentrations of $3 \mathrm{mg} / \mathrm{L}$ SWCNTs and $5 \mu \mathrm{M}$ siRNA. The choice of final siRNA concentration was based on the initial siRNA concentration suspended in the siRNA buffer and probably exceeded the actual concentration of siRNA complexed to and taken into cells by SWCNTs. Treated cells were incubated under normoxic conditions at $37^{\circ} \mathrm{C}$ for $72 \mathrm{~h}$ and then transferred into a hypoxic chamber ( $1 \%$ oxygen) for an additional $18 \mathrm{~h}$. HIF- $1 \alpha$ activity was found to be significantly inhibited in cells treated with the SWCNT-siHIF-1 $\alpha$ complex, but unchanged in cells treated with the SWCNT/siSC complex (Fig. 4 (a)). We confirmed by Western blot

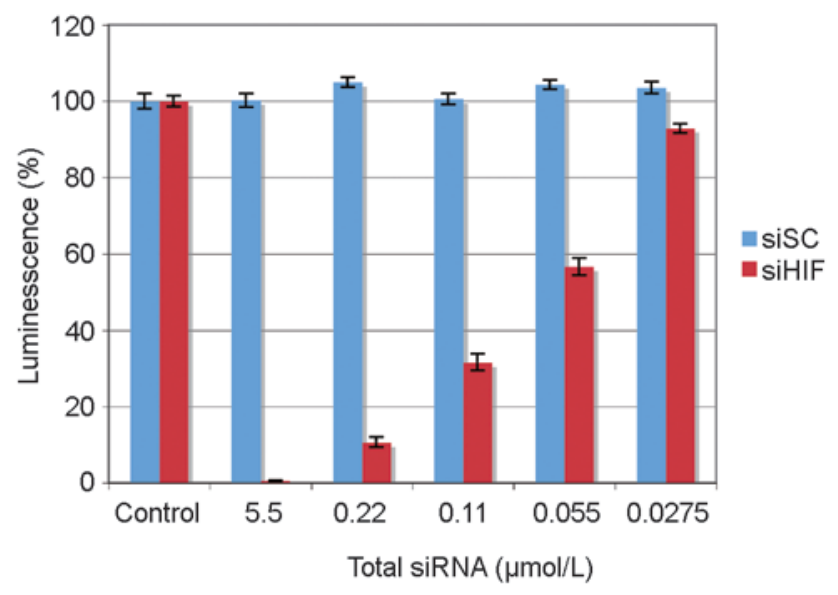

(a)

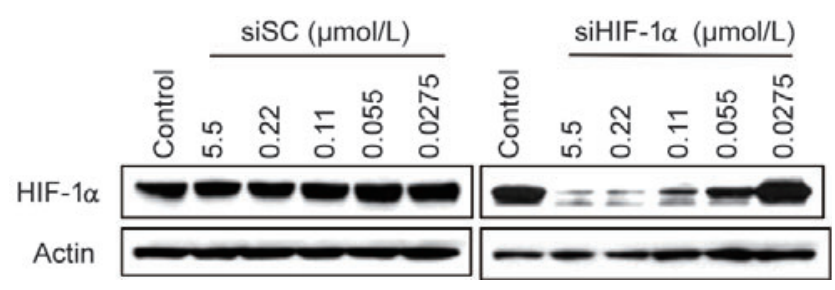

(b)

Figure 4 siRNA delivered into cells by pristine SWCNTs induces the RNAi response. Complexes of either SWCNT/non-targeting siRNA (siSC) or SWCNT/siRNA targeting HIF-1 $\alpha$ (siHIF- $1 \alpha$ ) were added to cells growing in normal media containing $10 \%$ FCS. Non-transfected parental cells (control) and siRNA transfected cells were incubated under normoxic conditions at $37^{\circ} \mathrm{C}$ for $72 \mathrm{~h}$ and under hypoxic conditions ( $1 \%$ oxygen) at $37^{\circ} \mathrm{C}$ for $18 \mathrm{~h}$. HIF- $1 \alpha$ activity was determined by the luciferase assay (a) and HIF-1 $\alpha$ protein expression by Western blot (b) 
that the inhibition of HIF-1 $\alpha$ activity was the result of knockdown of the protein (Fig. 4(b)). The loss of HIF- $1 \alpha$ activity and protein knockdown correlated well in a concentration-dependent manner. Because knockdown of the HIF-1 $\alpha$ protein was observed only in cells treated with SWCNT/ siHIF-1 $\alpha$ complexes, we conclude that siRNAs retain their ability to induce a specific RNAi response after delivery into cells by complexation with pristine SWCNTs.

\subsection{RNAi response in multiple cell types induced by SWCNT/siRNA complexes}

We next added SWCNT/siRNA complexes to cultures of pancreatic cancer cells (MiaPaCa2), breast cancer cells (MCF-7, MDA-MB-231), and ovarian cancer cell line (RGM1) to determine whether SWCNTs could deliver siRNA into a wide range of cell types to induce the RNAi response. We observed (Fig. 5) that non-targeting siRNA (siSC) demonstrated negligible toxicity to the cancer cells tested while siTox and siKif11 both induced cell death in transfected cells. siRNA targeting KIf11 is a toxic siRNA commonly used to confirm transfection efficiency. Our observation that delivery of siKif11 into cancer cells

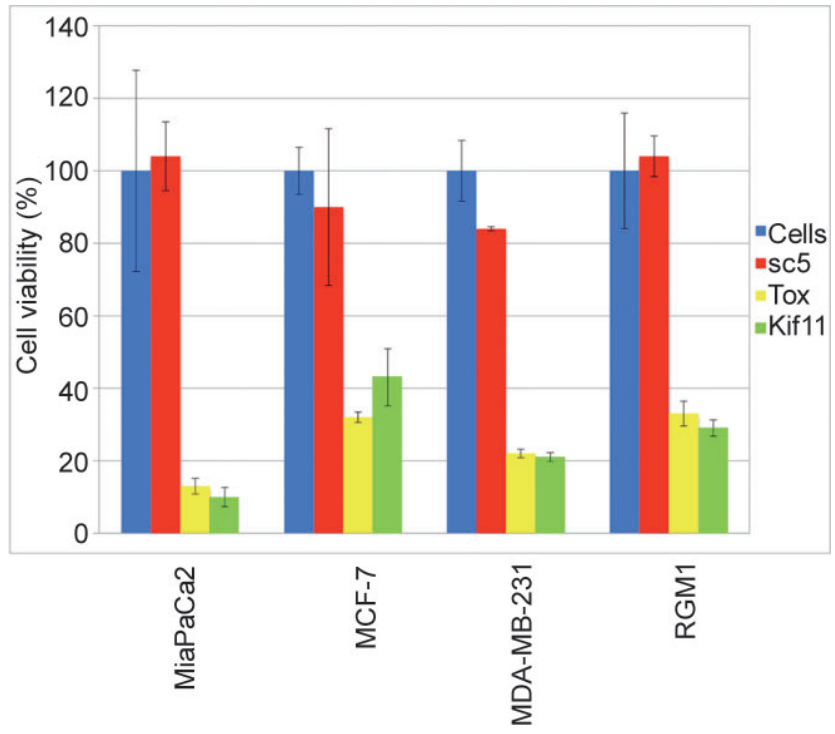

Figure 5 siRNA delivered into a range of cancer cells by pristine SWCNTs induces the RNAi response with similar efficiency. Complexes of either SWCNT/non-targeting siRNA (siSC), SWCNT/ siRNA targeting Kif11 (siKif11) or SWCNT/siRNA Tox (siTox) at a final concentration of $5 \mathrm{~mol} / \mathrm{L}$ were added to cells growing in normal media containing $10 \%$ FCS. Cells were incubated at $37^{\circ} \mathrm{C}$ for $72 \mathrm{~h}$. Cell viability was determined by the WST-1 assay was toxic to these cells suggests that SWNCTs have the potential to function as a serum-insensitive, wide range transfection agent for delivery of siRNA into cancer cells to induce the RNAi response.

2.6 Inhibition of HIF-1 $\alpha$ activity in a xenograft mouse tumor by intratumoral administration of SWCNT/ siRNA complexes

We used a xenograft mouse tumor model to investigate the ability of SWCNT/siHIF complexes to inhibit HIF-1 $\alpha$ activity in vivo. The siRNA buffer used to generate the SWCNT/siRNA complexes for the in vitro studies contains potassium and cannot be used in in vivo studies. We therefore selected $0.9 \%$ saline solution as our alternative to the siRNA buffer. To demonstrate that we can achieve a similar biological outcome using SWCNT/siRNA complexes in saline, complexes in $0.9 \%$ saline were prepared at several concentrations as described for the siRNA buffer and added to MiaPaCa-HRE pancreatic cancer cells growing in normal media containing $10 \%$ FCS. In this experiment we used siRNA targeting polo-like kinase 1 (PLK1), a protein that plays an important role in the G2-M transition and whose silencing results in cell death. Determination of cell viability is a quick and efficient indicator of transfection efficiency as well as of induction of the RNAi response. We found that changing to the saline environment gave no significant change in biological activity of the SWCNT/siRNA complexes at the concentrations used for the animal study (Fig. 6 (a)). To study the effectiveness of targeting MiaPaCa-HRE cells in vivo, we subcutaneously injected cell suspensions into the right flanks of 6 to 8-week-old female athymic nude mice $(\mathrm{nu} / \mathrm{nu})$. Activation of HIF- $1 \alpha$ in the hypoxic environment of the growing tumor was confirmed by imaging the bioluminescence of luciferin. As MiaPaCa cell lines do not express HIF- $2 \alpha$ these images allow us to effectively monitor HIF- $1 \alpha$ activity in vivo in the xenograft mouse model (Figs. 6 (b) and 6 (c); red indicates the highest luciferase concentration, followed by yellow and green; blue represents bleedthrough). We observed significantly decreased tumor HIF- $1 \alpha$ activity in mice treated with SWCNT/HIF complexes compared to those treated with complexes comprising either the control SWCNT/siRNA 
$(p<0.01$ to $p<0.05)$ or HIF- $1 \alpha$ siRNA alone (Fig. 6 (d)). However, no suppression of tumor volume was observed (Fig. 6 (e)), a result that we attribute to incomplete inhibition of HIF-1 $\alpha$. To test this possibility, we carried out an ex vivo experiment in which MiaPaCa-HRE parental cells, cells transfected with a control SWCNT/siRNA complex, and SWCNT/siHIF complex were grown in tissue culture for $24 \mathrm{~h}$ prior to being injected subcutaneously into mice. Tumor growth was monitored over a period of 33 days. We observed that tumors generated by the parental cells and those transfected with the control siRNA grew similarly and at a faster rate compared to tumors transfected with the siRNA targeting
HIF-1 $\alpha$ (Data not shown). An initial period of growth inhibition in this latter group accounted for its slow rate of growth compared to the other two groups. As the tumors were harvested on day 33, together with the fact that protein silencing by siRNA is a transient effect usually lasting up to a week, it was no surprise to us that we failed to observe any significant difference in the levels of HIF-1 $\alpha$ between the three groups. We have shown that transfecting cells for periods longer than $6 \mathrm{~h}$ with siRNA/SWCNT results in both a significant uptake of the complexes into the cells (Fig. 2) and silencing of HIf- $1 \alpha$ expression (Fig. 4 (b)) and conclude therefore, that the initial growth inhibition observed in our ex vivo study was most

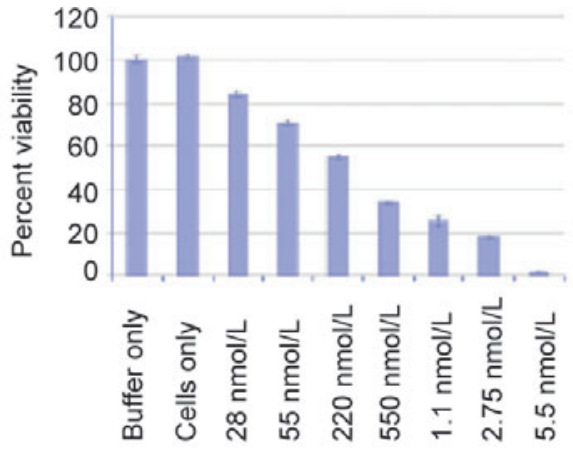

Concentration of siRNA

(a)

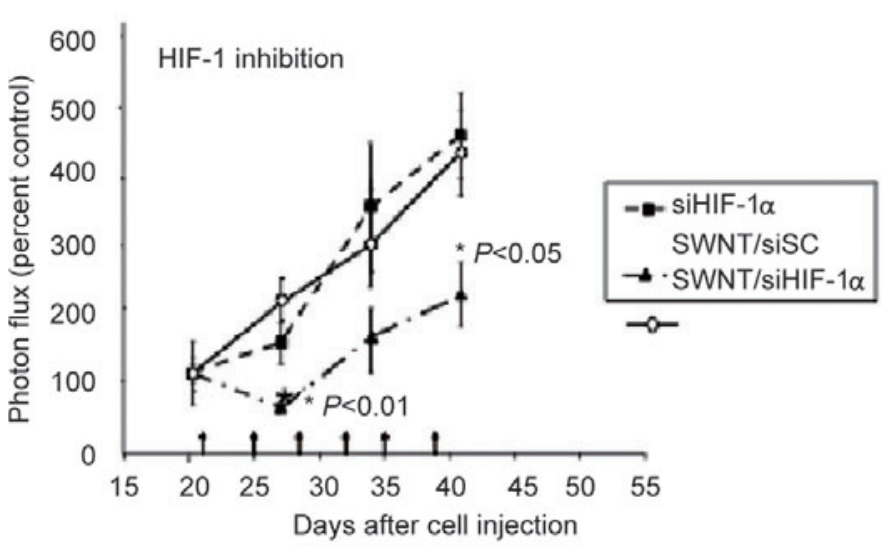

(d)

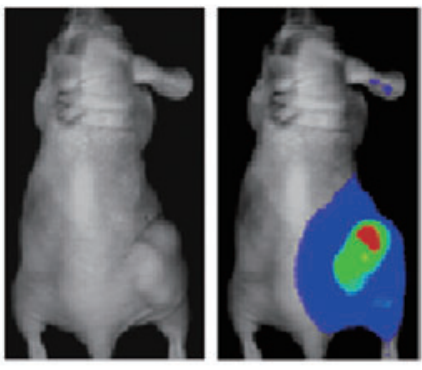

(b)

(c)

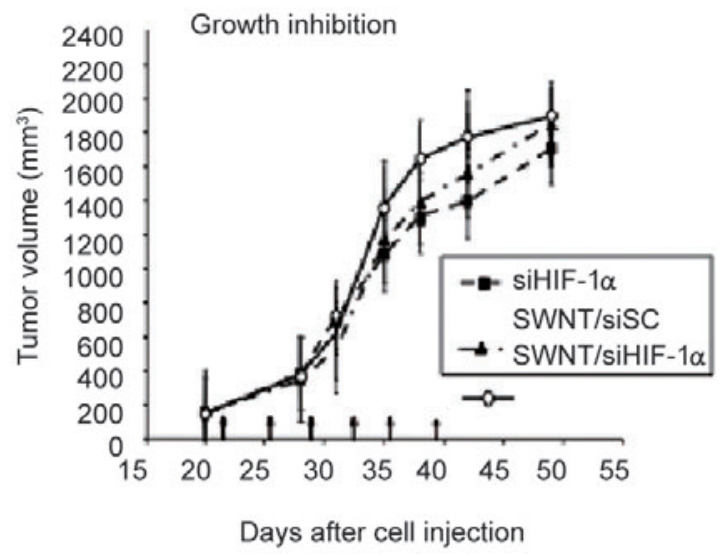

(e)

Figure 6 Intratumor administration of SWCNT/siRNA complexes inhibits HIF-1 $\alpha$ activity in a xenograft mouse tumor. (a) A range of concentrations of SWCNT-siPLK complexes in a $0.9 \%$ saline solution were added to MiaPaCa-HRE pancreatic cancer cells growing in media containing $10 \%$ FCS. Cell viability was determined $72 \mathrm{~h}$ after treatment. At average tumor volumes of $150-200 \mathrm{~mm}^{3}$, tumor-bearing mice were imaged using xenogeny prior to the addition of luciferin (b) and 5 min after the addition of luciferin (c). (d) Tumor-bearing mice were divided into three groups (eight mice per group) and given intratumoral injections of either siRNA targeting HIF-1 $\alpha$ alone (siHIF-1 $\alpha$ ), a non-targeting siRNA complexed to SWCNTs (SWCNT/siSc), or siRNA targeting HIF-1 $\alpha$ complexed to SWCNTs (SWCNT-siHIF) twice per week for 3 weeks (on days marked by arrows). Changes in HIF-1 $\alpha$ activity within the tumor were monitored by imaging for luciferase expression twice per week for the duration of the study. (e) The anti-tumor effect was monitored by measuring tumor volumes twice per week for the duration of the study 
probably due to the complete inhibition of HIF-1 $\alpha$.

The awareness of the clinical relevance of carbon nanotubes has raised questions about its toxicity. The evidence of toxicity is mainly derived from studies focused on the adsorption of large carbon nanostructures via inhalation or dermal exposure [38]. In addition, carbon nanoparticles and multiwalled nanotubes with diameters in excess of $20 \mathrm{~nm}$, have inhibited the growth of cultured human lung cancer cells [28]. Surprisingly, even at high concentrations, toxicity has not been observed following intravenous administration of either pristine or functionalized SWNTs [39-42]. No mortality or loss of mass of mice as well as no evidence of toxicity in tissues and organs were observed in these studies that ranged in time from $24 \mathrm{~h}$ to 6 months after treatment.

Our results demonstrate that siRNA can be used to solubilize pristine SWCNTs and that noncovalent SWCNT/siRNA complexes can transfect cancer cells and effectively silence a targeted gene in cell culture and also in tumors in vivo. The use of synthetic siRNA serves as a powerful tool to silence target genes with a high degree of specificity and is a potential novel approach for targeted cancer therapy [15]. In this study we used many different siRNA sequences to complex the pristine SWNCTs, and observed that irrespective of their nucleotide sequences these siRNA solubilized the SWCNTs equally effectively. This differs from other reports that the ability of single-stranded DNA to solubilize pristine SWNTs is dependent on the GC content of the nucleotide sequence. (Bruce Weisman, unpublished results). Whether these differences are associated with the use of single-stranded or double-stranded nucleotide sequences remains to be determined however.

Efficient intracellular transport and delivery of siRNA are critical to the potency and in vivo therapeutic activity of RNAi. We observed internalization of the SWCNT-siRNA complex in about $30 \%$ of the treated cells $1 \mathrm{~h}$ after addition of the complex to cells growing in media containing 10\% serum. By $3 \mathrm{~h}$ post treatment, internalized SWCNTs were observed in more than $90 \%$ of cells and the number of internalized SWCNTs per cell increased further after $6 \mathrm{~h}$. These findings suggest the capability of introducing siRNA into nearly all of the cells in a culture, a result usually achieved only through viral gene delivery. Whereas viral vectors can have the drawbacks of inducing immune responses, inflammation, and (potentially) oncogenic effects [43], the SWCNT delivery agent appears nontoxic to most cells.

It is noteworthy that the delivery of siRNA by SWCNTs occurred even in the presence of serum. Serum proteins can bind to the surface of SWCNTs in a non-specific manner and this spontaneous adsorption is usually seen on acid-oxidized water soluble SWCNTs [16, 44]. Small proteins such as streptavidin $(60 \mathrm{kD})$ adsorb more readily to the sidewalls of individual SWCNTs while large proteins such as fibrinogen (340 kD) adsorb poorly [45]. In addition, the binding of proteins to carbon nanotubes depends on the physical organization of the nanotubes. Fibrinogen has a strong binding affinity to the surface of nonwoven nanotubes whereas albumin, even at high concentrations failed to bind to this surface [45]. Studies with ssDNA have suggested that the flexibility of this molecule allows it to find low energy conformations that maximize base-nanotube stacking interactions while exposing the hydrophilic sugar phosphate backbone to the water [29]. We hypothesize that the inability of serum proteins to significantly influence the activity of the SWCNT/ siRNA could be due either to the weak binding of the proteins to the pristine nanotubes or the inability of the proteins to displace siRNA from the nanotube surface, possibly because the hydrophilic sugar phosphate backbone can block protein adsorption. Further studies will be needed to clarify the kinetic and thermodynamic factors controlling interactions of serum proteins with SWCNT/ siRNA complexes.

Lipid reagents have successfully been used to deliver siRNA into cancer cells. When we compared the effectiveness of SWCNTs and lipid reagents as delivery agents of siRNA we observed that they were comparable in their ability to delivery siRNA into cells to induce the RNAi response. There were however significant differences. Commercial lipid reagents are very cell line specific and to obtain optimum transfection conditions with minimum toxicity requires selecting the best reagent from a panel of lipid reagents. The SWCNTs are much less cell line dependent and have negligible toxic effects on most cell lines. In 
addition, lipid reagent transfections have to be carried out in the absence of serum which is toxic to cells, while SWCNTs transfections can be carried out in the presence of serum. This suggests that SWCNTs have the potential to be developed into a universal delivery agent for siRNA.

The simple sonication-based protocol for forming SWCNT/siRNA complexes evidently does not functionally damage the siRNA, as cells exposed to the complexes display a clear RNAi response. We found that both HIF- $1 \alpha$ activity and protein levels were lowered by approximately $70 \%$ to $80 \%$ when the pristine SWCNTs delivered siRNA targeting HIF-1 $\alpha$ mRNA into the host cancer cells. An intriguing question arises as to how the complexed siRNA induces the RNAi response. One possibility is that siRNA dissociates from the SWCNTs inside the cell; another is that siRNA molecules retain their RNAi activity while still complexed with nanotubes. Additional research is needed to resolve this important question.

Although we chose to target HIF-1 $\alpha$ in these studies, the approach can be applied to other targets for RNAi. As these SWCNT-siRNA complexes can enter most cells in their present composition but appear to be rather rapidly cleared from the blood, we used direct intratumoral injection to demonstrate that pristine SWCNTs can deliver HIF-1 $\alpha$-targeting siRNA into tumor cells. Further studies are underway to prepare SWCNT-siRNA complexes that can function therapeutically following systemic administration.

\section{Conclusions}

We have demonstrated a simple and inexpensive method, involving no chemical reactions, for preparing soluble complexes of siRNA and pristine SWCNTs. The complexes are effective in silencing target genes both in vitro and in vivo with a high degree of specificity and minimal toxicity. We have demonstrated that our complexes of siRNA and pristine SWCNTs can transfect and induce the RNAi response in a range of cancer cells. This promising technology deserves further investigation for use as a therapeutic strategy against multiple tumor types.

\section{Acknowledgements}

This research was supported in part by grants to the M. D. Anderson Cancer Center from the NIH (CA-77204 and CA-109552) and to Rice University from the Welch Foundation (C-0807), the NSF Center for Biological and Environmental Nanotechnology (EEC-0647452), and the Alliance for NanoHealth (NASA JSC-NNJ06HC25G). We thank Christine Moran for assistance with sample preparation.

\section{References}

[1] Hoeckel, M.; Schlenger, K.; Hoeckel, S.; Vaupel, P. Hypoxic cervical cancers with low apoptotic index are highly aggressive. Cancer Res. 1999, 59, 4525-4528.

[2] Brown, J. M. Exploiting the hypoxic cancer cell: Mechanisms and therapeutic strategies. Mol. Med. Today 2000, 6, 157-162.

[3] Brown, J. M. \& Giaccia, A. J. The unique physiology of solid tumors: Opportunities (and problems) for cancer therapy. Cancer Res. 1998, 58, 1408-1416.

[4] Unruh, A.; Ressel, A.; Mohamed, H. G.; Johnson, R. S.; Nadrowitz, R.; Richter, E.; Katschinski, D. M.; Wenger, R. $\mathrm{H}$. The hypoxia-inducible factor- $1 \alpha$ is a negative factor for tumor therapy. Oncogene 2003, 22, 3213-3220.

[5] Aebersold, D. M.; Burri, P.; Beer, K. T.; Laissue, J.; Djonov, V.; Greiner, R. H.; Semenza, G. L. Expression of hypoxiainducible factor-1 $\alpha$ : A novel predictive and prognostic parameter in the radiotherapy of oropharyngeal cancer. Cancer Res. 2001, 61, 2911-2916.

[6] Zhang, X. W.; Kon, T.; Wang, H.; Li, F.; Huang, Q.; Rabbani, Z. N.; Kirkpatrick, J. P.; Vujaskovic, Z.; Dewhirst, M. W.; Li, C. Y. Enhancement of hypoxia-induced tumor cell death in vitro and radiation therapy in vivo by use of small interfering RNA targeted to hypoxia-inducible factor $-1 \alpha$. Cancer Res. 2004, 64, 8139-8142.

[7] Talks, K. L.; Turley, H.; Gatter, K. C.; Maxwell, P. H.; Pugh, C. W.; Ratcliffe, P. J.; Harris, A. L. The expression and distribution of the hypoxia-inducible factors HIF-1 $\alpha$ and HIF- $2 \alpha$ in normal human tissues, cancers, and tumorassociated macrophages. Am. J. Path. 2000, 157, 411421.

[8] Zhong, H.; De Marzo, A. M.; Laughner, E.; Lim, M.; Hilton, D. A.; Zagzag, D.; Buechler, P.; Isaacs, W. B.; Semenza, G. L.; Simons, J. W. Overexpression of hypoxia- 
inducible factor $1 \alpha$ in common human cancers and their metastases. Cancer Res. 1999, 59, 5830-5835.

[9] Semenza, G. L. Targeting HIF-1 $\alpha$ for cancer therapy. Nat. Rev. Cancer 2003, 3, 721-732.

[10] Liao, D.; Corle, C.; Seagroves, T. N.; Johnson, R. S. Hypoxia-inducible factor- $1 \alpha$ is a key regulator of metastasis in a transgenic model of cancer initiation and progression. Cancer Res. 2007, 67, 563-572.

[11] Stoeltzing, O.; McCarty, M. F.; Wey, J. S.; Fan, F.; Liu, W. B.; Belcheva, A.; Bucana, C. D.; Semenza, G. L.; Ellis, L. M. Role of hypoxia-inducible factor $1 \alpha$ in gastric cancer cell growth, angiogenesis, and vessel maturation. J. Natl. Cancer Inst. 2004, 96, 946-956.

[12] Maxwell, P. H.; Dachs, G. U.; Gleadle, J. M.; Nicholls, L. G.; Harris, A. L.; Stratford, I. J.; Hankinson, O.; Pugh, C. W.; Ratcliffe, P. J. Hypoxia-inducible factor- $1 \alpha$ modulates gene expression in solid tumors and influences both angiogenesis and tumor growth. Proc. Natl. Acad. Sci. USA 1997, 94, 8104-8109.

[13] Ryan, H. E.; Poloni, M.; McNulty, W.; Elson, D.; Gassmann, M.; Arbeit, J. M.; Johnson, R. S. Hypoxiainducible factor- $1 \alpha$ is a positive factor in solid tumor growth. Cancer Res. 2000, 60, 4010-4015.

[14] Kung, A. L.; Wang, S.; KIco, J. M.; Kaelin, W. G.; Livingston, D. M. Suppresion of tumor growth through disruption of hypoxia-inducible transcription. Nat. Med. 2000, 6, 1335-1340.

[15] Dykxhoorn, D. M.; Lieberman, J. Knocking down diseases with siRNA. Cell 2006, 126, 231-235.

[16] Kam, N. W. S.; Dai, H. Carbon nanotubes as intracellular protein transporters: Generality and biological functionality. J. Am. Chem. Soc. 2005, 127, 6021-6026.

[17] Kam, N. W. S.; Liu, Z.; Dai, H. Functionalization of carbon nanotubes via cleavable disulfide bonds for efficient intracellular delivery of siRNA and potent gene silencing. J. Am. Chem. Soc. 2005, 127, 12492-12493.

[18] Kam, N. W. S.; Jessop, T. C.; Wender, P. A; Dai, H. Nanotube molecular transporters: Internalization of carbon nanotubes-protein conjugates into mammalian cells. J. Am. Chem. Soc. 2004, 126, 6850-6851.

[19] Zhang, Z. H.; Yang, X. Y.; Zhang, Y.; Zeng, B.; Wang, Z. J.; Zhu, T. H.; Roden, R. B. S.; Chen, Y. S.; Yang, R. $C$. Delivery of telomerase reverse transcriptase small interfering RNA in complex with positively charged single-walled carbon nanotubes suppresses tumor growth. Clin. Cancer Res. 2006, 12, 4933-4939.
[20] Cherukuri, P.; Bachilo, S. M.; Litovsky, S. H.; Weisman, R. B. Near-infrared flourescence microscopy of sinngledwalled carbon nanotubes in phagocytic cells. J. Am Chem. Soc. 2004, 126, 15638-15639.

[21] Tasis, D.; Tagmatarchis, N.; Georgakilas, V.; Prato, M. Soluble carbon nanotubes. Chem. Eur. J. 2003, 9, 40004008.

[22] Bianco, A.; Kostarelos, K.; Prato, M. Application of carbon nanotubes in drug discovery. Curr. Opin. Chem. Biol. 2005, 9, 674-679.

[23] Pantarotto, D.; Singh, R.; McCarthy, D.; Erhardt, M.; Briand, J. P.; Prato, M.; Kostarelos, K.; Bianco, A. Functionalized carbon nanotubes for plasmid DNA gene delivery. Angew. Chem. Int. Ed. 2004, 43, 5242-5246.

[24] Tasis, D.; Tagmatarchis, N.; Bianco, A.; Prato, M. Chemistry of carbon nanotubes. Chem. Rev. 2006, 106, 1105-1136.

[25] Zhao, W.; Song, C.; Pehrsson, P. E. Water-soluble and optically $\mathrm{pH}$-sensitive single-walled carbon nanotubes from surface modification. J. Am. Chem. Soc. 2002, 124, 12418-12419.

[26] He, P.; Urban, M. W. Controlled phospholipid functionalization of single-walled carbon nanotubes. Biomacromolecules 2005, 6, 2455-2457.

[27] Liu, Z.; Winters, M.; Holodniy, M.; Dai, H. siRNA delivery into human $\mathrm{T}$ cells and primary cells with carbonnanotube transporters. Angew. Chem. Int. Ed. 2007, 46, 1-6.

[28] Magrez, A.; Kasas, S.; Salicio, V.; Pasquier, N.; Seo, J. W.; Celio, M.; Catsicas, S.; Schwaller, B.; Forro, L. Cellular toxicity of carbon-based nanometrials. Nano Lett. 2006, 6, 1121-1125.

[29] Zheng, M.; Jagota, A.; Semke, E. D.; Diner, B. A.; Mclean, R. S.; Lustig, S. R.; Richardson, R. E.; Tassi, N. G. DNAassisted dispersion and separation of carbon nanotubes. Nat. Mater. 2003, 2, 338-342.

[30] Dwyer, C.; Guthold, M.; Falvo, M.; Washburn, S.; Superfine, R.; Erie, D. DNA-functionalized single-walled carbon nanotubes. Nanotechnology 2002, 13, 601-604.

[31] Nepal, D.; Sohn, J. I.; Aicher, W. K.; Lee, S. J.; Geckeler, K. E. Supramolecular conjugates of carbon nanotubes and dna by a solid-state reaction. Biomacromolecules 2005, 6, 2919-2922.

[32] Zheng, M.; Jagota, A.; Strano, M. S.; Santos, A. P.; Barone, P.; Chou, S. G.; Diner, B. A.; Dresselhaus, M. S.; McLean, R. S.; Onoa, G. B.; Samsonidze, G. G.; Semke, 
E. D.; Usrey, M.; Walls, D. J. Structure-based carbon nanotubes sorting by sequence-dependent dna assembly. Science 2003, 302, 1545-1548.

[33] Nikolaev, P.; Bronikowski, M. J.; Bradley, R. K.; Rohmund, F.; Colbert, D. T.; Smith, K. A.; Smalley, R. E. Gas-phase catalytic growth of single-walled carbon nanotubes from carbon monoxide. Chem. Phys. Lett. 1999, 313, 91-97.

[34] Tsyboulski, D. A.; Bachilo, S. M.; Weisman, R. B. Versatile visualization of individual single-walled carbon nanotubes with near-infrared fluorescence microscopy. Nano Lett. 2005, 5, 975-979.

[35] PaineMurrieta, G. D.; Taylor, C. W.; Curtis, R. A.; Lopez, M. H. A.; Dorr, R. T.; Johnson, C. S.; Funk, C. Y.; Thompson, F.; Hersh, E. M. Human tumor models in the severe combined immune deficient (scid) mouse. Cancer Chemother Pharmacol. 1997, 40, 209-214.

[36] Svensson, R. U.; Barnes, J. M.; Rokhlin, O. W.; Cohen, M. B.; Henry, M. D. Chemotherapeutic agents upregulate the cytomegalovirus promoter: implications for bioluminescence imaging of tumor response to therapy. Cancer Res. 2007, 67, 10445-10454.

[37] Cherukuri, P.; Gannon, C. J.; Leeuw, T. K.; Schmidt, H. K.; Smalley, R. E.; Curley, S. A.; Weisman, R. B. Mammalian pharmacokinetics of carbon nanotubes using intrinsic near-infrared fluorescence. Proc. Natl. Acad. Sci. USA 2006, 103, 18882-18886.

[38] Singh, R.; Pantarotto, D.; Lacerda, L.; Pastorin, G.; Klumpp, C.; Prato, M.; Bianco, A.; Kostarelos, K. Tissue biodistribution and blood clearance rates of intravenously administered carbon nanotube radiotracers. Proc. Natl. Acad. Sci. USA 2006, 103, 3357-3362.
[39] Liu, Z.; Davis, C.; Cai, W. B.; He, L.; Chen, X. Y.; Dai, H. J. Circulation and long-term fate of functionalized, biocompatible single-walled carbon nanotubes in mice probed by Raman spectroscopy. Proc. Natl. Acad. Sci. USA 2008, 105, 1410-1415.

[40] Liu, Z.; Cai, W. B.; He, L. N.; Nakayama, N.; Chen, K.; Sun, X. M.; Chen, X. Y.; Dai, H. J. In vivo biodistribution and highly efficient tumour targeting of carbon nanotubes in mice. Nat. Nanotechnol. 2007, 2, 47-52.

[41] Schipper, M. L.; Nakayama-Ratchford, N.; Davis, C. R.; Kam, N. W. S.; Chu, P.; Liu, Z.; Sun, X. M.; Dai, H. J.; Gambhir, S. S. A pilot toxicology study of single-walled carbon nanotubes in a small sample of mice. Nat. Nanotechnol. 2008, 3, 216-221.

[42] Yang, S. T.; Guo, W.; Lin, Y.; Deng, X. Y.; Wang, H. F.; Sun, H. F.; Liu, Y. F.; Wang, X.; Wang, W.; Chen, M.; Huang, Y. P.; Sun, Y. P. Biodistribution of pristine singlewalled carbon nanotubes in vivo. J. Phys. Chem. 2007, 111, 17761-17764.

[43] Thomas, C. E.; Ehrhardt, A.; Kay, M. A. Progress and problems with the use of viral vectors for gene therapy. Nat. Rev. Genet. 2003, 4, 346-358.

[44] Fu, K.; Huang, W.; Lin, Y.; Zhang, D.; Hanks, T. W.; Rao, A. M.; Sun, Y. P. Functionalization of carbon nanotubes with bovine serum albumin in homogeneous aqueous soultions. J. Nanosci. Nanotech. 2002, 2, 457-461.

[45] Meng, J.; Song, L.; Xu, H.; Kong, H.; Wang, C.; Guo, X.; $\mathrm{Xie}, \mathrm{S}$. Effect of single-walled carbon nanotubes on the functions of plasma proteins and potentials in vascular prostheses. Nanomed. Nanotechnol. Biol. and Med. 2005, 1, 136-142. 